\title{
Original Research Article \\ Diagnostic Utility of Fine Needle Aspiration Cytology and Cell Block Technique in Thyroid Lesions
}

\author{
Authors \\ Dr Shobhana J Agrawal ${ }^{1}$, Dr Suwarna B Patil ${ }^{2}$, Dr Pradeep S Umap ${ }^{3}$, \\ Dr Jasleenkaur S Oberoi ${ }^{4}$, Dr Shailesh S Agrawal ${ }^{5}$ \\ ${ }^{1,4}$ Junior Resident III Department of Pathology, GMC, Akola, Maharashtra, India \\ ${ }^{2}$ Associate Professor, Department of Pathology, GMC, Akola, Maharashtra, India \\ ${ }^{3}$ Professor and Head, Department of Pathology, GMC, Akola, Maharashtra, India \\ ${ }^{5}$ Senior Resident, Department of Pulmonary Medicine, PGIMER, Chandigarh, India \\ *Corresponding Author
}

Dr. Jasleenkaur S Oberoi

\begin{abstract}
Introduction: Thyroid diseases are among the commonest endocrine disorders worldwide. In order to avoid misdiagnosis and hence unnecessary surgery in patients with benign thyroid nodules, it is essential to distinguish between benign and malignant lesions. Despite the proven clinical importance of thyroid FNAC, it still has limitations. To overcome these limitations to some extent Cell Block technique can be used. It has a pivotal role in diagnosis and ancillary studies. In this study, we evaluated the role of Cell Block as a useful adjunct to cytological smears for establishing a more definitive Cytopathological diagnosis.

Material and Methods: Present study was a prospective cross sectional study conducted from Nov 2017 to Oct 2019. 334 cases with thyroid swelling underwent FNAC. Of these 334, Cell Blocks were prepared by plasma thromboplastin method for 273 cases and histopathology was available for 66 cases.

Results: In this study, the age range was 8-76 years. Maximum number of cases were 96 (28.75\%) in age group of 31-40 years. Female to male ratio was 10.1:1.The Sensitivity, Specificity, Positive predictive value, Negative predictive value and Diagnostic Accuracy of Cell Block in categorising neoplastic and non-neoplastic thyroid lesions was more than FNAC and when these two techniques were used together all statistical indices increased further.

Conclusion: Cell Block is a complimentary technique to cytological smears to increase the Sensitivity, Specificity and Diagnostic Accuracy in thyroid lesions.

Keywords: Thyroid lesion, FNAC, Cell Block, Adequacy, Diagnostic Accuracy.
\end{abstract}

\section{Introduction:}

Thyroid diseases are among the commonest endocrine disorders worldwide and in these diseases early diagnosis and treatment remain the cornerstone of management ${ }^{(1)}$. The thyroid swelling may be diffuse or nodular; may be solitary or multi-nodular. However, solitary nodules are more cause of concern due to the possibility of the nodule being malignant ${ }^{(2)}$.

Aspiration cytology as a routine diagnostic technique in diagnosis of palpable lesions of various organs was introduced by Martin HE and 
Ellis EB in 1930 and has proven to be the first line tool in the evaluation of a thyroid nodule ${ }^{(3)}$. It is simple, readily available, reliable, time saving, and minimally invasive procedure. Despite the proven clinical importance of thyroid FNAC, it still has few limitations like inadequate sampling, inability to define malignant follicular lesions in the absence of nuclear features of papillary carcinoma $^{(4)}$, false negative or positive results and a finding that is not obviously benign or malignant falls into the indeterminate or suspicious group ${ }^{(5)}$. To overcome these limitations to some extent, Cell Block (CB) technique can be used. CBs are micro biopsies embedded in paraffin, suitable for sectioning, staining, and microscopic study. It increases cellular yield and improves diagnostic accuracy. CB section retains histologic tissue architecture. The cellular material is more concentrated, less traumatized and less obscured by blood in the non-aspiration smears ${ }^{(6,7)}$. It has a pivotal role in diagnosis and ancillary studies.

The aims of the present study were1) To assess the role of FNAC in diagnosis of thyroid lesions 2) To assess the role of Cell block in diagnosis of thyroid lesion 3)To evaluate the importance of combined FNAC and cell block technique in diagnosis of thyroid lesions.

\section{Material and Methods}

Present prospective cross sectional study was conducted over two years from Nov 2017 to Oct 2019 at tertiary care hospital with available resources. During the study period, 334 cases with thyroid swelling underwent FNAC. Of these 334, Cell Blocks were prepared for 273 cases and diagnosis was compared with cytopathology. Subsequently 66 specimens were received for Histopathological examination and diagnosis was compared with cytological smear and cell block technique.

FNAC was done by routine procedure. For Cell Block preparation (plasma thromboplastin method $)^{(8)}$ the test tube with aspirated material was centrifuged at 3000 revolution per minute for 10 minutes. The supernatant fluid was decanted off. To the sediment, an equal amount of normal plasma and thromboplastin was added and mixed and then allowed to stand for 10-15 minutes. The cell ball formed was submitted to Histopathology section for processing as routine biopsy specimen. 4 to $5 \mu$ thick sections were made and stained with Haematoxylin-Eosin stain. Special stains like PAS, Congo Red, Masson's Trichrome and Reticulin were used wherever applicable. Stained sections were reported under microscope.

\section{Results}

In this study, the age range was 8-76 years. Maximum 96 (28.75\%) cases were in age group of $31-40$ years followed by $70(20.95 \%)$ in age group of 21-30 years. Out of 334 cases, 304 (91.02\%) were females and $30(8.98 \%)$ were males. Female to male ratio was 10.1:1. Non-neoplastic lesions were more common than neoplastic lesions both on FNAC and CB.

Out of 273 cases, FNAC was adequate in 237 $(86.81 \%)$ cases and Cell Block technique was adequate in 251 (91.94\%) cases. When CB technique was used with FNAC, 264 (96.70\%) cases were found to be adequate. The diagnosis of FNAC and CB was compared in 224 cases which were adequate on both FNAC and Cell Block (fig1), of which $209 \quad(93.30 \%)$ cases were correlated (Table 1) and 15 cases were discordant. Also, of these 224 cases,64 specimens were received for Histopathological examination and diagnosis was correlated in $51(80.95 \%)$ cases and 13 cases were discordant (Table 2 ).

CB showed better architecture and nuclear features (fig. 2). Colloid goiter was found to be the most common lesion overall as well as most common non-neoplastic lesion followed by lymphocytic thyroiditis on Cytology, CB and Histopathology. Follicular neoplasm was the most common neoplastic lesion followed by Huthle cell neoplasm on Cytology and CB. On Histopathology, follicular adenoma was the most common neoplastic lesion found. Medullary carcinoma, papillary carcinoma and anaplastic carcinoma was rare (fig 2). 


\section{JMSCR Vol||08||Issue ||07||Page 463-468||July}

The Sensitivity, Specificity, Positive predictive value, Negative predictive value and Diagnostic Accuracy of $\mathrm{CB}$ in categorising neoplastic and non-neoplastic lesions was more than FNAC and when these two techniques were used together, all statistical indices increased further (Table 3).

Table 1: Distribution of cases with correlated diagnosis on FNAC and Cell Block

\begin{tabular}{|l|c|c|c|}
\hline CATEGORY & DIAGNOSIS & FREQUENCY & PERCENT \\
\hline \multirow{4}{*}{ Non-neoplastic } & $\begin{array}{c}\text { Colloid goiter/Colloid } \\
\text { nodule/Colloid cyst }\end{array}$ & 129 & $61.72 \%$ \\
\cline { 2 - 4 } & Lymphocytic thyroiditis & 40 & $19.14 \%$ \\
\cline { 2 - 4 } & Hashimoto's thyroiditis & 13 & $6.22 \%$ \\
\cline { 2 - 4 } & Granulomatous thyroiditis & 7 & $3.35 \%$ \\
\hline \multirow{3}{*}{ Neoplastic } & Follicular neoplasm & 3 & $6.22 \%$ \\
\cline { 2 - 4 } & Hurthle cell neoplasm & 1 & $0.48 \%$ \\
\cline { 2 - 4 } & Papillary carcinoma & 3 & $1.44 \%$ \\
\cline { 2 - 4 } & Medullary carcinoma & $\mathbf{2 0 9}$ & $\mathbf{1 0 0 \%}$ \\
\hline
\end{tabular}

(*Neoplastic- Benign +Malignant)

Table 2: Distribution of cases with discordant diagnosis on FNAC, Cell Block and Histopathology

\begin{tabular}{|c|c|c|c|}
\hline FNAC & CELL BLOCK & HISTOPATHOLOGY & $\mathbf{N}$ \\
\hline \multirow[b]{5}{*}{ Colloid goiter } & \multirow[b]{2}{*}{ Colloid goiter } & Hashimoto's thyroiditis & 1 \\
\hline & & Follicular adenoma & 1 \\
\hline & Hashimoto's thyroiditis & Hashimoto's thyroiditis & 1 \\
\hline & \multirow[t]{2}{*}{ Follicular neoplasm } & Follicular adenoma & 1 \\
\hline & & Colloid goiter & 1 \\
\hline \multirow[t]{2}{*}{ Colloid nodule } & \multirow[b]{2}{*}{ Follicular neoplasm } & Follicular adenoma & 1 \\
\hline & & $\begin{array}{l}\text { Follicular adenoma with } \\
\text { colloid nodule }\end{array}$ & 1 \\
\hline $\begin{array}{l}\text { Lymphocytic } \\
\text { Thyroiditis }\end{array}$ & Lymphocytic thyroiditis & Colloid goiter & 1 \\
\hline \multirow[t]{2}{*}{ Follicular neoplasm } & \multirow[b]{2}{*}{ Colloid goiter } & Follicular adenoma & 2 \\
\hline & & Colloid goiter & 2 \\
\hline $\begin{array}{l}\text { Hurthle cell } \\
\text { Neoplasm }\end{array}$ & Papillary carcinoma & Papillary carcinoma & 1 \\
\hline \multicolumn{3}{|c|}{ TOTAL } & 13 \\
\hline
\end{tabular}

Table 3: Comparison of statistical indices of FNAC, Cell Block and combined FNAC andCell Block technique

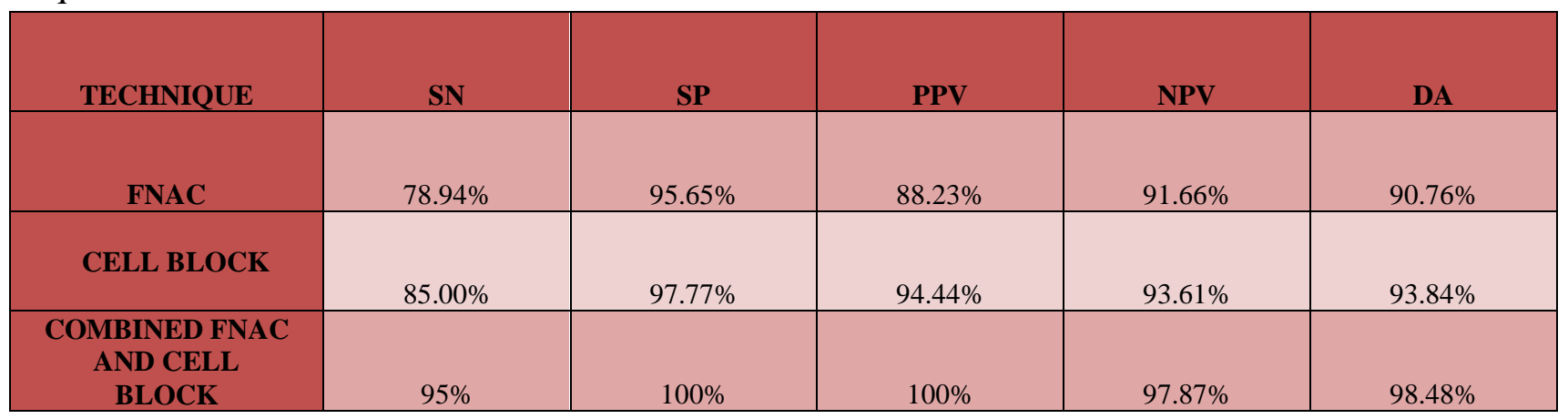

Table 4: Comparison of adequacy of FNAC, Cell Block and combined FNAC and Cell Block with other studies

\begin{tabular}{|c|c|c|c|}
\hline & \multicolumn{3}{|l|}{$\overline{\text { ADEQUACY }}$} \\
\hline AUTHOR (YEAR) & FNAC & $\begin{array}{c}\text { CELL } \\
\text { BLOCK }\end{array}$ & $\begin{array}{l}\text { FNAC + CELL } \\
\text { BLOCK }\end{array}$ \\
\hline Kuo et al. & $78.45 \%$ & $76.3 \%$ & $85.1 \%$ \\
\hline Ceyhan et al. & $92.8 \%$ & $84.8 \%$ & $93.5 \%$ \\
\hline Present study & $89.92 \%$ & $91.94 \%$ & $96.70 \%$ \\
\hline
\end{tabular}




\section{JMSCR Vol||08||Issue ||07||Page 463-468||July}

Figure 1: Comparison of adequacy of FNAC and Cell Block in 273 cases

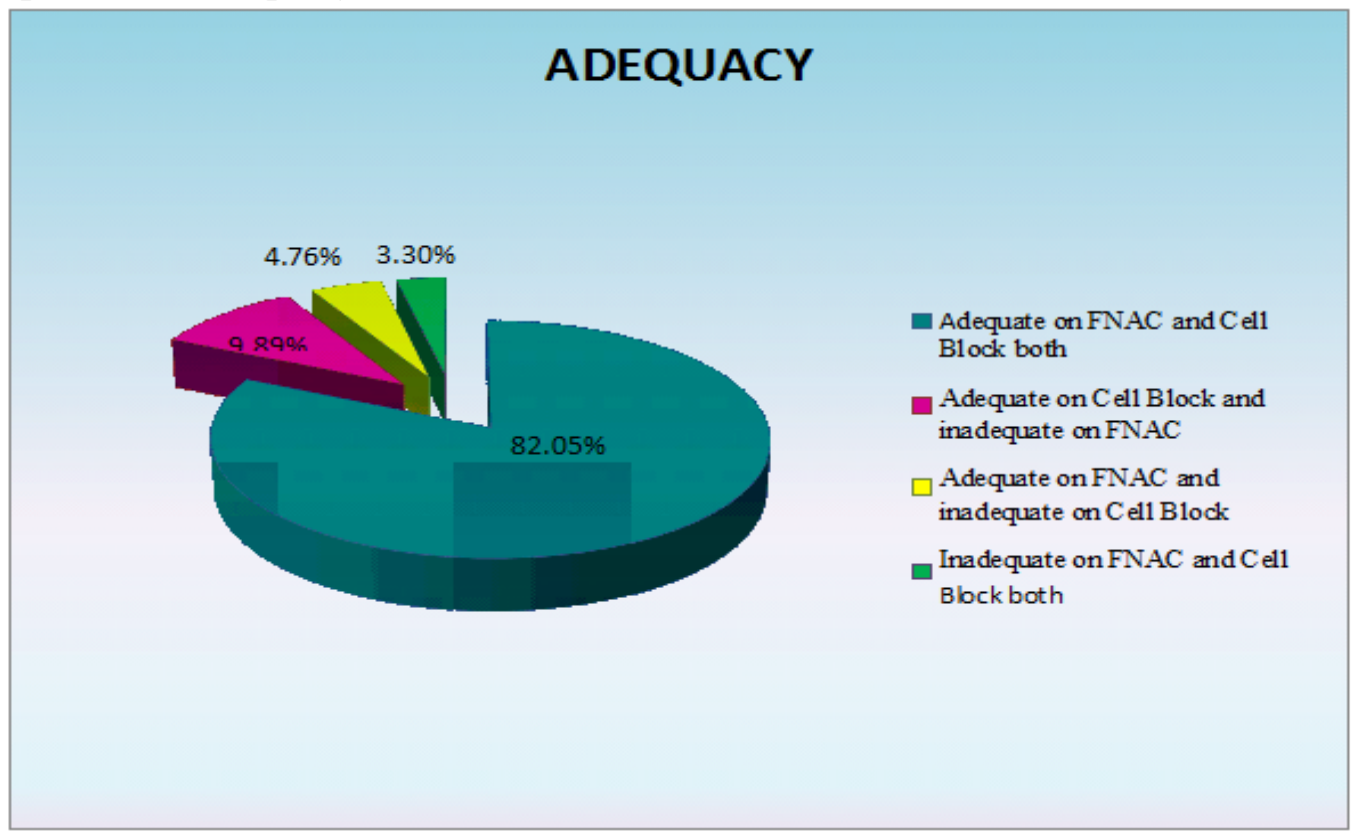

Figure 2: Microphotographs of different thyroid lesions on Cell Block (H \& E, 400X)

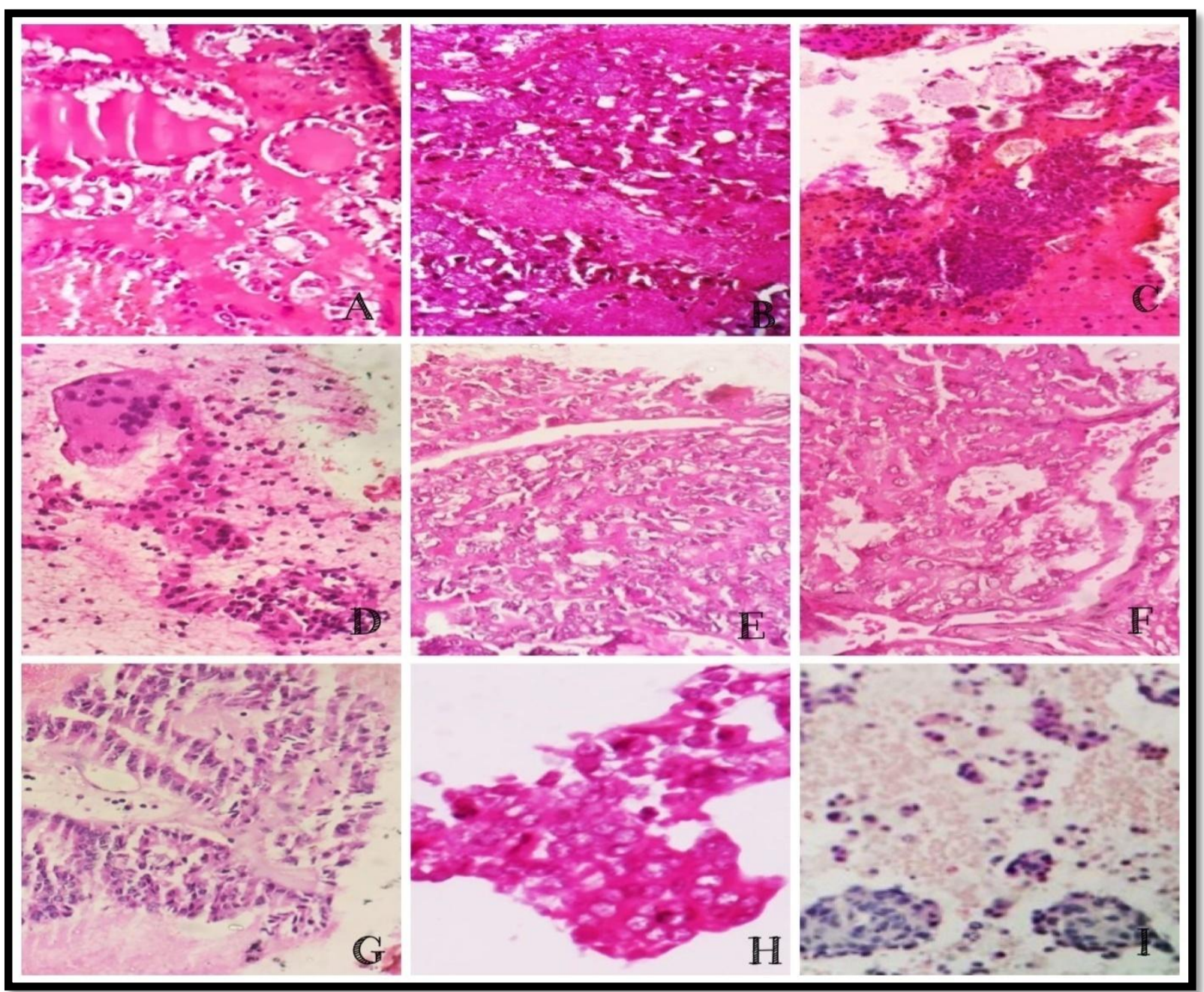

A: Colloid goiter; B: Colloid goiter with colloidophages; C: Lymphocytic thyroiditis; D: Hashimoto's thyroiditis; E: Follicular Neoplasm; F:Hurthle cell Neoplasm; G:Papillary thyroid carcinoma; H: Papillary thyroid carcinoma showing nuclear features; I: Medullary carcinoma 


\section{Discussion}

In the clinical practice it is necessary to distinguish reliably the few malignant thyroid lesions from the harmless thyroid lesions, so that a definitive planning of appropriate surgery and relevant patient counselling can be done ${ }^{(9)}$. Since most of the thyroid nodules are benign, symptomless and small in size, they do not require surgical excision ${ }^{(10)}$. In order to avoid misdiagnosis and hence unnecessary surgery in patients with benign thyroid nodules, it is essential to distinguish between benign and malignant lesions.

FNAC is used as a routine diagnostic technique in diagnosis of thyroid lesions and is regarded as the single most accurate and cost-effective procedure (3).Despite the proven clinical importance, thyroid FNAC has some limitations like inadequate sampling, false negative or positive results and difficulty in classifying lesions. $\mathrm{CB}$ technique overcomes these limitations to some extent. CB may give a better result than FNAC because of good fixation of the specimens as well as good interrelation between the cells. This also reduces the range of inadequacy ${ }^{(11)}$. The cell block enabled a better interpretation of morphology of the papillae or follicles along with the study of nuclear features. In addition, numerous sections can be obtained which can be used for special stains and immunohistochemistry. This technique has many added advantages but has few disadvantages too. CBs are not always sufficient. Thus, CB technique should be used as adjuvant to FNAC.

In present study, we found a wide range of age distribution with youngest patient being 8 years and oldest was of 76 years. We compared results of present study of utility of CB of thyroid lesions over FNAC with studies available in literature. Thyroid lesions were more common in females with female to male ratio ranging from $5: 1$ to 9.6:1 in various studies and 10.1:1 in this study.

In present study, we found that the adequacy of $\mathrm{CB}$ in thyroid lesions was more than FNAC and the adequacy of combined FNAC and CB was more than FNAC or CB alone like in studies done by Kuo et al. (2004) ${ }^{(12)}$ and Ceyhan et al. $(2006)^{(13)}$ (Table 3). Also the non-neoplastic lesions were more than neoplastic lesions on FNAC, CB and Histopathology. Colloid goiter was found to be the commonest diagnosis as well as the commonest non-neoplastic lesion. Among neoplastic lesions, follicular neoplasm (follicular adenoma on Histopathology) was the most common diagnosis. Studies done by Zarika Ahmed et al. (2015) ${ }^{(14)}$, Divyesh Goswami et al. $(2016)^{(15)}$ and Gayathri Devi Thanigaimanin et al. $(2016)^{(16)}$ observed the same.

Ana Patrica de Cristo et al. ${ }^{(17)}$ studied the increasing diagnostic effectiveness of thyroid nodule evaluation by implementation of cell block preparation in routine Cytodiagnosis in 2016. They found that cyto-cell block interpretation improved the efficiency of FNAC. When CB used as adjuvant to cytology all statistical indices were found to be increased than FNAC or CB alone.Despite the proven advantages few disadvantages of CB technique are: 1) Increased processing time 2) Increased cost as compared to smear cytology3) Delay in diagnosis.

Overall, the advantages of CB technique are much more than disadvantages. It not only increases the diagnostic yield but also gives accurate diagnosis than cytological smear in many thyroid lesions. FNAC and CB together provide better additional information for diagnosis, improve the diagnostic accuracy and decrease the false positive results which can help in appropriate patient management and in avoiding unnecessary excisional biopsies.

\section{Conclusion}

The Cell Block (CB) preparation increases cellular yield of FNA by capturing small fragments in haemorrhagic aspirates and allowing the recovery $\&$ processing of minute amount of cellular material. Serial sections can be used for ancillary studies and it can be stored for long period for future studies. It bridges the gap between cytology and histopathology. 


\section{JMSCR VoI||08||Issue ||07||Page 463-468||July}

Despite their utility, cell blocks are not always sufficient so it should be used as adjuvant to FNAC. Cell block is complimentary to cytology but cannot replace it

\section{Acknowledgment}

Dean, Government Medical College and Hospital, Akola.

\section{References}

1. Unnikrishnan A, Menon U. Thyroid disorders in India: An epidemiological perspective. Indian $\mathrm{J}$ Endocrinol Metab. 2011;15(6):78.

2. Furlanetto TW, Peccin S, Schneider M de O, Zimmer A dos S, dos Reis PS, Genro SK, et al. Prevalence of thyroid nodules in 40 years-old or old women. Rev Assoc Médica Bras. 2000;46(4):331-334.

3. Amrikachi M, Ramzy I, Rubenfeld S, Wheeler TM. Accuracy of fine-needle aspiration of thyroid: a review of 6226 cases and correlation with surgical or clinical outcome. Arch Pathol Lab Med. 2001;125(4):484-488.

4. Fischer S, Asa SL. Application of immunohistochemistry to thyroid neoplasms. Arch Pathol Lab Med. 2008;132(3):359-372.

5. Galera-Davidson H. Diagnostic problems in thyroid FNAs. Diagn Cytopathol 1997; 17(6):422-428.

6. Fagelman D, Chess Q. Nonaspiration fineneedle cytology of the liver: a new technique for obtaining diagnostic samples. AJR Am J Roentgenol. 1990;155(6):12171219.

7. Yue XH, Zheng SF. Cytologic diagnosis by transthoracic fine needle sampling without aspiration. ActaCytol. 1989;33(6):805-808.

8. Koss L, Melamed M. Laboratory Techniques. In: Koss' Diagnostic cytology \& its Histopathologic Bases.5th ed. Philadelphia: Lippincott Williams \& Wilkins; 2006. p. 1590-3.
9. Goswami D, Agrawal P, Shinde P. Accuracy of fine needle aspiration cytology (FNAC) in comparison to histopathological examination for the diagnosis of thyroid swellings. Int $\mathrm{J}$ Med Sci Public Health. 2017;6(1):6-11.

10. Pandit AA, Kinare SG. Fine needle aspiration cytology of thyroid.Indian $\mathbf{J}$ Cancer. 1986;23(1):54-58.

11. Hegazy RA, Hegazy AA. FNAC and Cellblock Study of Thyroid Lesions. Univers $\mathbf{J}$ Med Sci. 2013;8.

12. Kuo F-Y, Chen W-J, Lu S-N, Wang J-H, Eng H-L.Fine needle aspiration cytodiagnosis of liver tumors. Acta Cytol. 2004;48(2):142-148.

13. Ceyhan K, Kupana SA, Bektaş M, Coban S, Tuzun A, Cinar K, et al. The diagnostic value of on-site cytopathological evaluation and cell block preparation in fine-needle aspiration cytology of liver masses. Cytopathology. 2006;17(5):267-274.

14. Ahmed Z, Medhi P, Das D. DIAGNOSTIC UTILITY OF CELL BLOCKS IN THYROID ASPIRATES. J Evol Med Dent Sci. 2015 Sep 21;4(76):13221-32.

15. Goswami D, Agrawal P, Shinde P. Accuracy of fine needle aspiration cytology (FNAC) in comparison to histopathological examination for the diagnosis of thyroid swellings. Int $\mathrm{J}$ Med Sci Public Health. 2017;6(1):6-11.

16. Thanigaimani GD, Murali P. FNAC and Cell Block Study in Thyroid Lesions. Sch J App Med Sci. 2016;4(6C):2070-3.

17. Cristo AP de, Goldstein HF, Faccin CS, Maia AL, Graudenz MS. Increasing diagnostic effectiveness of thyroid nodule evaluation by implementation of cell block preparation in routine US-FNA analysis. Arch Endocrinol Metab. 2016;60(4):367373. 